\title{
Lugares de memória da imigração na América Latina: As hospedarias dos imigrantes de São Paulo e Buenos Aires
}

\author{
Eloisa Helena Capovilla da Luz Ramos \\ Maíne Barbosa Lopes \\ UNISINOS
}

\section{Introdução}

Beatriz Sarlo, ${ }^{1}$ ao discutir a temática do bicentenário da Independência na Argentina, sublinhou que as suas imagens da pátria não estavam em símbolos como o hino ou a bandeira nacional, mas se encontravam em fotografias do começo do século XX, nas quais apareciam centenas de imigrantes recém chegados ao país - período em que mais adentraram estrangeiros na Argentina. Para a autora, esta era a imagem que representava o país no primeiro centenário da independência.

Queremos ressaltar com esta reflexão de Sarlo que, no processo de formação dos Estados Latino-americanos, a presença de imigrantes em sua formação é um fator inegável. Se o movimento das populações européias para a América se faz desde o século XVI, em maior ou menor escala e tem inúmeros momentos de emigração, não se pode deixar de sublinhar um deles, em especial, em que tal fenômeno se acentua e que se dá entre os anos de 1870 e 1930, quando se estima que "mais de 30 milhões de pessoas tenham cruzado o Atlântico migrando do Velho para o Novo Mundo".2

Considerando esses dois olhares sobre a temática da imigração, que afirmam e reafirmam a presença e a importância dos imigrantes nesses países, mas ampliando o leque de possibilidades de análise do fenômeno, queremos estudar a memória e as representaçóes construídas pelos e sobre os imigrantes europeus que vieram para o Brasil e para a Argentina no período compreendido entre os anos de 1870 a 1930. Tais aspectos serão olhados a partir do estudo de dois museus - o Memorial do Imigrante de 
São Paulo e a Hospedaria dos Imigrantes de Buenos Aires - porque são espaços representativos da história da imigração. Ou seja, "são lugares onde a memória defende-se da dissolução". ${ }^{3}$ Levamos em conta também, nesse estudo, que esta memória de tempos em tempos é (res)significada e re(a)presentada nestes espaços museológicos.

\section{A imigração e a construção de memórias}

A história da emigração/imigração deve ser aqui referenciada na medida em que foi no seu bojo que se desenvolveu a experiência vivenciada por distintos grupos em diferentes épocas e que deram aos países do Cone Sul, em especial o Brasil e a Argentina, características próprias e uma cultura marcada pela influência dos países de origem desses diferentes grupos. Essa influência aparece, dentre outros lugares, nos fragmentos da cultura material expostos nos museus estudados que passaram a abrigar uma memória representada pelo modo de vida imigrante, oriunda do processo histórico e cultural que foram as migrações internacionais.

Emigrar, do latim emigrare, quer dizer deixar um país, geralmente o de origem, para ir estabelecer-se em outro. ${ }^{4}$ Nessa perspectiva, é cortar laços, é cortar o cordão umbilical. É deixar para trás um tipo de vida e tudo que ela envolve. "Era a pobreza o que encaminhava a maioria para os portos de onde saíam os navios para uma nova vida”, diz Moura. ${ }^{5}$ Imigrar é palavra cujo significado está ligado ao "ato de entrar num país estrangeiro, para nele viver". 'Ser imigrante, por seu turno, envolve o desconhecido, o novo. Pressupõe o vou ocupar um lugar que ainda não sei qual é, em um país onde nunca esteve e sobre o qual tenho muitas expectativas. Viver em um novo país, ser estrangeiro, traz consigo uma carga diferenciada para o imigrante, pois o obriga a pensar-se como o outro, a ter que se adaptar e readaptar.

Tomada na perspectiva de Sayad, “a imigração é em primeiro lugar, um deslocamento de pessoas no espaço /.../ físico", 7 o que nos leva a dizer que ser imigrante é, fundamentalmente, ser de outro lugar. É ser percebido como um estrangeiro no país de adoção e, nessa condição, viver provisoriamente nesse país. Como apontou o mesmo autor, "o imigrante só existe na sociedade que assim o denomina a partir do momento em que atravessa suas fronteiras e pisa seu território; o imigrante nasce nesse dia para a sociedade que assim o designa". ${ }^{8}$ Um imigrante é, então, alguém que deixou sua terra natal para buscar trabalho noutro país e lá, marcado como estrangeiro, viver com a esperança de voltar para sua 
terra (embora na maioria das vezes saiba que não voltará). Nesse sentido, é uma experiência que nos parece nostálgica.

Para Miguel Monteiro,

migração e emigração são, no contexto dado, expressões que designam a deslocação de indivíduos do seu território geográfico, social e familiar, por um determinado tempo, na suposição do retorno ao sítio de saída /.../. Confrontam-se, neste caso, dois lugares distintos: o da saída e o de destino, ou seja, há rupturas de natureza social, familiar e afectiva no movimento migratório.?

No desdobramento do processo migratório, duas questões são, ainda, ressaltadas: a de que os emigrantes, até o último quartel do século XIX, quando deixaram seus lugares de origem não o fizeram como alemães ou como italianos, mas como mecklemburgueses, renanos, genoveses, venezianos e aqui, quer no Brasil quer na Argentina tiveram uma identidade atribuída sendo nominados alemães ou italianos; e a de que, quando empreenderam o movimento de emigração, os emigrantes fizeram mais do que um deslocamento físico. Eles trouxeram consigo bagagens, dentre as quais roupas e objetos. Suas malas, ou melhor, seus baús, sacos e trouxas continham pertences de diferentes valores. Alguns, dentre esses pertences tinham valor simbólico, porque estavam ligados às histórias pessoais do grupo que se deslocava.

O imigrante, entretanto, não carregava uma bagagem simbólica e outra concreta, real. Além dos objetos, ele trazia as lembranças da terra que deixara e que vinham representadas pela língua falada, pelas histórias contadas, pelos cantos e contos e também pelas imagens da terra natal que, da retina, deslocaram-se para a memória. Lúcia Lippi Oliveira nos diz que

essa viagem significou um profundo rompimento com a vida anterior e deixou marcas naqueles que a empreenderam. O sofrimento [de alguns] pelo que estavam deixando e a ansiedade pelo que deveriam encontrar marcam os relatos daqueles que emigraram. ${ }^{10}$

Aos objetos trazidos foi atribuído valor de lembranças dos familiares e do mundo deixado. O mesmo acontecerá com os livros de receita e de bordados, móveis e objetos de trabalho que passarão agora a ser objetos portadores de outra memória. "Muitos remontam no novo lar certas marcas trazidas da casa de origem"11, diz Oliveira. São "retratos de família, imagens religiosas, objetos de decoração" 12 ou outros sinais que possam lembrar o lugar de onde vieram. Tais constataçôes nos permitem reafirmar que o 


\section{Dôssie Imigração}

espaço dos deslocamentos era, além de político e econômico, também social e cultural. Sendo assim, quem vai ocupar um lugar significativo na vida destes imigrantes é a memória.

Vista como fonte de experiência e como um dos suportes da identidade individual ou coletiva, a memória está relacionada com a história desses personagens e, quando embasada nas lembranças provocadas por vestígios do passado poderá desempenhar a sua função social, através de liturgias próprias $^{13}$. Por isso, "o seu conteúdo é inseparável dos seus campos de objetivação e de transmissão - linguagem, imagens, relíquias, lugares, escrita, monumentos - e dos ritos que o reproduzem. O que mostra que, nos indivíduos, não haverá memória coletiva sem suportes de memória ritualisticamente compartilhados" ${ }^{14} \mathrm{Ou}$ seja, não existe memória sem traços.

Nesse contexto, as lembranças comuns e as repetições rituais como as festas familiares, aliadas à conservação de saberes e de símbolos do grupo entre os quais se contam as fotografias, as histórias, os saberes e fazeres ou mesmo odores e sabores de comidas típicas, assim como a responsabilidade de transmitir esta herança, serão fatores fundamentais para a construção de um sentimento de pertença ao grupo e, conseqüentemente, para a construção de uma identidade. É Candau quem nos alerta que

Sin memoria, el sujeto se pierde, vive únicamente el momento, pierde sus capacidades conceptuales y cognitivas. Su mundo estalla en pedazos y su identidad se desvanece. Sólo produce un sucedáneo de pensamiento, un pensamiento sin duración, sin el recuerdo de su génesis, condición necesaria para la conciencia y para la conciencia de uno mismo. ${ }^{15}$

Catroga nos diz ainda que "como instância solidificadora de identidades, compreende-se que a expressão coletiva da memória /.../ não escape à instrumentalização dos poderes através da seleção do que se recorda e do que consciente ou inconscientemente se silencia". ${ }^{16}$ Memória e esquecimento são, neste caso, faces de uma mesma moeda.

Neste recorte se inserem, também, os museus porque eles são lugares de guardar a memória, mas são, ao mesmo tempo, lugares de re(a)presentação dessa memória ao público. Um museu, em sua organização, expressa diferentes aspectos da sociedade em que está inserido e relaciona os objetos expostos com o que foi produzido ou guardado por tal sociedade. Concomitante a esta re(a)presentação, o museu faz uma interpretação da sociedade através da expografia e da exposição que a desenvolve. 
Estamos cientes que toda sociedade produz objetos, quer em escala artesanal, quer em escala industrial. Isto não torna os objetos produzidos peças de museu, mas quando tais artefatos são retirados do convívio do grupo e colocados nos espaços museológicos, há uma mudança de perspectiva e esta é, quase sempre, um indicativo de que a comunidade ou o grupo familiar produtor ou possuidor desse bem cultural está buscando preservá-lo ou quer imprimir a marca da sua cultura na sociedade em que está inserido. Tais objetos que já se tinham tornado possuidores de um capital afetivo no seio do grupo que os possuía, passarão a acumular, também, um capital de memória ao serem reapresentados ao público através das exposiçõos.

\section{(Re)elaboração e re(a)presentação das memórias imigrantes}

$\mathrm{O}$ ato da investidura dos objetos nos museus os transfigura. Eles adquirem, a partir desse momento, outro valor, pois ao serem musealizados serão também investidos da veracidade do testemunho. $\mathrm{Na}$ medida em que são recolhidos, os objetos passam a testemunhar uma ação, um trabalho, uma diversão. Não são mais pratos, copos, talheres, toalhas, vestidos ou mobiliário, mas testemunhos históricos de um banquete, de um casamento ou da vida cotidiana de homens, mulheres e crianças imigrantes.

Nesses objetos museais está, portanto, presente e inscrita uma representação cultural da sociedade uma vez que tais objetos têm caráter de testemunho, além de atuarem na função de comunicação, já que expor é comunicar. É dessa forma que os diferentes papéis sociais, tais como a riqueza e o trabalho, assim como os distintos caminhos percorridos pelos imigrantes podem ser vistos e lidos nos museus que os re(a)presentam em diversos suportes. Os objetos expostos serão vistos nestes espaços como livros, cujas histórias permitirão, também, múltiplas interpretações sobre a imigração.

Os cenários museológicos elaborados com objetos oriundos da imigração e a sua posterior leitura é que vão nos permitir, em última instância, perceber a construção de uma representação sobre os imigrantes. Neste caso, a representação será construída a partir das peças contidas no acervo dos museus e sua competência narrativa será avaliada pela sua capacidade de re(a)presentação do grupo imigrante.

Não podemos pensar, porém, que os objetos expostos falam por s'. Menezes nos adverte que 
o que faz um objeto documento não é uma carga latente, definida de informação que ele encerre, pronta para ser extraída, como um sumo de limão. /.../ É, pois, a questão do conhecimento que cria o sistema documental. O historiador não faz o documento falar: é o historiador quem fala /.../. Toda operação com documentos, portanto é de natureza retórica. Não há por que o documento material deva escapar destas trilhas que caracterizam qualquer pesquisa histórica" ${ }^{17}$.

No museu, então, a comunicação entre o público, de origem imigrante ou não, e a exposição poderá resultar em uma ou muitas interpretações, já que o público, como o sujeito principal da recepção, levará também seu cabedal de conhecimentos e não precisará manter fidelidade ao conceito da exposição que visita. Isto quer dizer que podemos fazer várias leituras de uma exposição, além daquela(s) proposta(s) por seus organizadores. Podemos dizer, ainda, que uma exposição terá sempre em seu bojo, um discurso. Independente do grupo organizador, uma exposição é sempre um conceito distendido em forma expositiva.

Partindo destas considerações é que vamos analisar a bagagem cultural trazida pelos imigrantes e mostrada nas exposições de longa duração das antigas Hospedarias dos Imigrantes de São Paulo e Buenos Aires, hoje Museu e Memorial da Imigração. Tal bagagem será tomada neste texto como corpus documental tridimensional, acrescida de textos-fonte, além de fotografias publicadas e de outros materiais on line e folhetos, que nos permitirão aprofundar o estudo sobre como são re(a)presentados os imigrantes nos museus citados.

Em história, lembra Certeau, "tudo começa com o gesto de separar, de [re]unir, de transformar em 'documentos' certos objetos distribuídos [originariamente] de outra maneira" ${ }^{18}$. É o caso dos objetos tridimensionais que formam as coleções museológicas. Nossa escolha deveu-se também ao fato desses espaços terem assumido funções de guardiães da memória imigrante nas duas maiores cidades do Cone Sul e de seus edifícios ainda serem testemunhos desta ação nas citadas cidades. Sendo instituições de caráter museológico que "colecionam, documentam, preservam exibem e interpretam evidências materiais [e imateriais] e informação associada para o benefício público", ${ }^{19}$ estes espaços são, ao mesmo tempo, lugares de memória e espaços de (re)elaboração e re(a)presentação dessa memória imigrante.

São Paulo abriga a antiga Hospedaria dos Imigrantes, localizada no Brás. Ela foi o espaço destinado a abrigar os recém-chegados nos seus primeiros dias no Brasil, nos idos de 1887. Por ali passaram cerca de 2,5 
milhões de imigrantes até 1978. Hoje, a Hospedaria transformou-se no Memorial do Imigrante. Em seu acervo, assim como na exposição de longa duração que costuma organizar, muitos fragmentos materiais e imateriais de origem imigrante assinalam a história daquele movimento populacional. ${ }^{20}$

O estudo da antiga Hospedaria ao longo de sua história nos mostra que no seu espaço era possível receber até mil imigrantes por dia, sendo que o máximo de tempo de permanência destes homens e mulheres, nesse lugar de passagem, era de seis a oito dias, período que necessitavam para a organização de seus contratos de trabalho. Lá dormiam, faziam as refeições, recebiam atendimento médico e conseguiam seus empregos. ${ }^{21}$ "A Hospedaria era dotada de dormitórios, cozinhas e refeitórios, uma lavanderia, uma enfermaria, um dispensário médico" 22 e outras dependências indispensáveis ao bom funcionamento da casa como os banheiros e a peça onde se fazia a desinfecção das roupas dos que chegavam. Quanto ao refeitório, era formado por 80 mesas onde os imigrantes faziam quatro refeições diárias, compostas, geralmente, por pão, carne verde, feijão, arroz, batata ou verdura, café e açúcar. ${ }^{23}$

$\mathrm{O}$ que traziam os imigrantes em suas bagagens? Segundo Soraya Moura,

alguns imigrantes chegavam sem nada, outros, mais precavidos traziam consigo uma série de coisas, tais como utensílios de cozinha, máquinas de costura, fotografias, relíquias de família e peças que lembrassem a terra natal. Tais pertences geralmente eram transportados em sacos, sacolas, em caixas improvisadas ou, até mesmo enrolados em esteiras. / .../ Cada passageiro de terceira classe podia transportar até 100 quilos de bagagem gratuita. ${ }^{24}$

No espaço museológico do Memorial do Imigrante de São Paulo, portanto, os objetos e utensílios expostos têm sua origem tanto no antigo mobiliário da casa quanto nas bagagens imigrantes. Assim, misturaramse, ao longo do tempo, instrumentos cirúrgicos e dentários e vestimentas; moedas e objetos de uso pessoal; malas e sapatos; fotografias e pratos; livros de oração e moedores de café; passaportes e periódicos, formando um acervo eclético, mas representativo dos grupos que vieram para o Brasil. Este acervo foi acrescido, também, pelas doaçôes da comunidade imigrante, por seus descendentes e pela história oral, o que denota a sua vontade de guardar memórias, quer em suportes tridimensionais, quer em suportes sonoros ou audiovisuais. ${ }^{25}$ Somam-se a estes objetos os documentos oficiais da imigração, que também são usados neste espaço para compor e recompor as memórias imigrantes. 
O Memorial do Imigrante tem como sua atribuição principal "a pesquisa, a coleta, a documentação, a preservação e a divulgação do acervo documental relativo aos imigrantes, que foi produzido pelos órgãos públicos" 26 brasileiros. É mister que se destaque ainda que "adquirir, preservar, pesquisar, documentar e divulgar a história da imigração e a memória dos imigrantes do Estado de São Paulo" 27 é, hoje, a missão principal dessa Instituição que, com esta atitude "procura homenagear homens e mulheres que, com seus sonhos, vontade de vencer e muito trabalho, transformaram São Paulo e o Brasil"28.

O Museu Hotel de Imigrantes de Buenos Aires foi inaugurado em 1911 para abrigar o crescente número de imigrantes que chegava à capital argentina. Seu objetivo era albergar em torno de 4.000 imigrantes. Seu espaço, bastante amplo, contava com dormitórios, um refeitório, enfermaria, oficinas de trabalho, além de muitos banheiros com água fria e quente e área com tanque para as mulheres lavarem as roupas. No período em que permaneciam no Hotel, em torno de cinco a sete dias, os imigrantes tinham acesso à sala de leitura onde havia mapas e livros sobre a Argentina e suas riquezas. Na parte térrea do edifício encontrava-se o grande refeitório. onde era servido o café da manhã, o almoço, a merenda e a janta, para até 1.000 pessoas por turno, ${ }^{29}$ o que nos permite perceber a dimensão do Hotel.

A vida cotidiana dos imigrantes, enquanto ficavam em suas dependências, era bastante organizada. As mulheres e as crianças ficavam juntas pela manhã, enquanto os homens buscavam trabalho ou iam para as oficinas. As refeiçôes eram feitas no refeitório e consistiam de café da manhã, almoço, merenda e ceia. No café da manhã havia café com leite, mate e pão assado na padaria do Hotel. O almoço era composto, via de regra, por um bom prato de sopa, guisado de carne com batatas e tempero, puchero, massa, arroz ou outro tipo de carne guisada. À tarde as crianças recebiam um lanche e à noite era servido o jantar. $\mathrm{Na}$ organização da vida cotidiana dos imigrantes, era possível, ainda, sair livremente, dispondo de tempo para conhecer a cidade ${ }^{30}$. Para os imigrantes o Hotel "era uma espécie de Oasis /.../ que serviu de nexo entre o trágico e conhecido, que havia ficado para trás, e o novo e desconhecido que teriam por diante". ${ }^{31}$

No início dos anos 1980, quando o Museu Hotel de Imigrantes foi organizado neste espaço, buscou-se formar o acervo museológico a partir de objetos e fotografias dos próprios imigrantes, assim como por objetos que haviam pertencido ao mobiliário do Hotel, como as camas e os móveis 
da enfermaria. Aquilo que não existia mais, como as camas, foi recriado. Os familiares dos imigrantes e as coletividades oriundas destes pioneiros é que cederam os objetos que vêm sendo exibidos, hoje, nos espaços da Hospedaria. $^{32}$

Compóe-se a exposição de longa duração deste museu por objetos como malas e baús; vestidos, casacos, sapatos e sombrinhas; óculos e máquinas fotográficas; passaportes, livros e jornais; ternos e gravatas assim como fotografias e instrumentos musicais. Esses objetos, que passaram a compor a exposição, passaram também a dizer dos imigrantes e do mundo por eles deixado. Ao seu lado, e completando a exposição, estão os documentos oficiais do próprio Ministério, como os registros da entrada dos imigrantes, as propagandas do novo país, o mapa da Argentina e as fotografias dos grupos. Dispersos no grande espaço, os objetos compõem um discurso e ajudam a desvendar parte do processo imigratório na Argentina.

Pari passu com a ação museológica, o Museu Hotel de Imigrantes em seu projeto se propôs a desenvolver também um roteiro para esta exposição de longa duração que o Museu apresenta. Tal instrumento de ajuda tem por objetivo destacar a importância da imigração na conformação [atual] da Nação Argentina, onde foram destacados os princípios que fundamentaram a política de portas abertas sustentada pelo Estado. ${ }^{33}$ Para os idealizadores do Museu Hotel de Imigrantes

Hablar de inmigración en la Argentina es hablar de la propria historia del país. El Museo Nacional de la Inmigración que las autoridades impulsan vigorosamente, pretende por um lado rendir homenaje a aquellos hombres e mujeres que hicieron Patria sin haber nacido en ella y por lo outro servir de fuente de interpretación de un fenómeno que alcanza a toda nuestra comunidad. ${ }^{34}$

O que se percebe, por fim, na organização deste Museu é que há, de forma que nos pareceu muito clara, uma intenção discursiva na montagem da exposição, já que ela primeiro mostra os imigrantes como 'os que vieram de lugares distantes em navios abarrotados e condições precárias', necessitando engajar-se na construção do padrão argentino de civilização e depois, os aponta como sujeitos importantes na formação da Nação Argentina.

\section{(In) conclusões}

Tomados em conjunto, podemos dizer que os propósitos do Memorial do Imigrante, em São Paulo, e do Museu Hotel de Imigrantes, em Buenos 
Aires, são muito semelhantes nos dois espaços. Primeiramente porque há, por parte dos que pensaram estes museus, uma intenção não velada de homenagear os grupos imigrantes, destacando a participação dos mesmos na construção das duas Nações.

Do ponto de vista dos acervos museais, os dois museus aproximam-se em seus guardados, embora o trabalho expográfico seja diferente e por isso traga resultados distintos, o que não impede que sejam vistos como lugares que guardam, conservam e expõem diversas materialidades e, por isso mesmo, apresentam-se como espaços de memória, que ajudam a compor/recompor identidades.

As memórias compostas a partir dos pertences imigrantes e que estão recolhidas, doadas ou depositadas nos museus pelas famílias imigrantes foi musealizada a partir de um conceito expográfico e reconta uma versão da história desses imigrantes. Os objetos retornam ao público, assim, com outra dimensão de análise e com a função de memória, de recordação, de re(a)presentação de uma etapa, de um momento determinado da vida desses grupos. A representação, tomada aqui como conceito que iluminou os objetos musealizados, foi buscada para dar a conhecer os imigrantes pelos objetos, pelas coisas trazidas e pelas lembranças. A representação, como mostra Chartier, ${ }^{35}$ é sempre "uma (re)apresentação do ausente" [o lugar, o país, a casa deixada, a vida nos tempos pioneiros]. Neste sentido, há uma identificação dos imigrantes pelos seus pertences em exposição.

Ao trazer os objetos e doá-los aos museus os imigrantes construíram e constroem uma memória para si, mas, ao compor a exposição nos espaços museológicos das antigas Hospedarias, hoje museus, criou-se igualmente uma memória e um perfil para estes imigrantes. Também ao arrolar o que se escreve sobre a importância dos imigrantes em folhetos de divulgação e outros produtos dentro do espaço museal, verificamos ainda a existência de mais uma forma de construção de representações sobre o imigrante.

\section{Notas e Referências}

1 Beatriz SARLO. “Los laureles que ¡supimos? Conseguir”. El Clarín, Bs. As, 25 de mayo de 2008.

2 Lucia Lippi OLIVEIRA. O Brasil dos imigrantes. Rio de Janeiro: Zahar Editores, 2001, p. 11.

3 Soraya MOURA. Memorial do Imigrante. A imigração no Estado de São Paulo. São Paulo: Imprensa Oficial, 2008, p. 129. 
4 MICHAELIS. Moderno dicionário da língua portuguesa. São Paulo: Ed. Melhoramentos, 1998, verbete emigrar, p.783.

5 MOURA. Op. Cit., nota 5, p. 21.

6 MICHAELIS, Op. Cit., nota 6, verbete imigrar, p. 1129.

7 Abdelmalek SAYAD. A imigração ou os paradoxos da alteridade. São Paulo: Editora da Universidade, 1998, p. 15.

8 Id.Ibidem, p.16.

9 Miguel MONTEIRO. "Migrantes e emigrantes de Fafe (1834-1926): territórios, estrutura social e itinerários', in 'Primeiras Jornadas de História Local”. Fafe: Câmara Municipal de Fafe, Portugal, 1996, p. 2. http://www.museu-

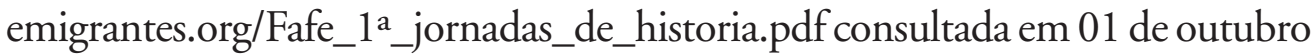
de 2010.

10 OLIVEIRA. Op. Cit. nota 4, p. 12.

11 Id. Ibidem, p. 12.

12 Id. Ibidem, p. 12.

13 Fernando CATROGA. “Memória e História”. In: Sandra Jatahy PESAVENTO. Fronteiras do milênio. Porto Alegre: Editora da Universidade/UFRGS, 2001, p. 48. 14 Id. Ibidem, p. 48.

15 Joël CANDAU. Antropologia de La memória. Buenos Aires: Nueva Visión, 2006, p. 5.

16 CATROGA. Op. Cit., nota 15, p. 59.

17 Ulpiano Toledo Bezerra de MENEZES. "Memória e cultura material: documentos pessoais no espaço público". Estudos Históricos. Rio de Janeiro: CPDOC/Fundação Getúlio Vargas, vol 11, n. 21, 1998, p. 9.

18 Michel de CERTEAU. A escrita da história. Rio de Janeiro: Forense Universitária, 1982 , p. 80.

19 Jose Gerardo Morales MORENO. 'Qué és um museo?'. Cuicuilco. Nueva Epoca, volumen 3, número 7, mayo/agosto de 1996, p. 72.

20 MOURA. Op. Cit., nota 4, p. 15.

21 Id. Ibidem, p. 75.

22 Id. Ibidem, p. 75.

23 Id. Ibidem, p. 90.

24 Id. Ibidem, p. 63.

25 O Memorial do Imigrante desenvolve programa de história oral, colhendo depoimentos de imigrantes e descendentes idosos.

26 http://www.memorialdoimigrante.org.br/portalmi/. Acessado em 16/11/2008.

27 http://www.memorialdoimigrante.org.br/portalmi. Acessado em 16/11/2008.

28 http://www.saopaulo.sp.gov.br/saopaulo/cultura/museus_imigracao.htm Acessado em 16/11/2008. 
29 BUENOS AIRES. Folheto de Divulgação - Museo Hotel de Inmigrantes, p. 5.

30 Id. Ibidem, p. 4.

31 Id. Ibidem, p. 1.

32 FOLHETO. Op. Cit., p. 5.

33 BUENOS AIRES - Programa Museo Hotel del Inmigrante, 1997, digitalizado, anexo 1 .

34 Ibidem, p. 19.

35 Roger CHARTIER. "Uma crise na história? A história entre narração e conhecimento”. In: Sandra Jatahy PESAVENTO. Fronteiras do milênio. Porto Alegre: Editora da Universidade/UFRGS, 2001, pp. 115-140. 